\title{
Genetically proxied inhibition of interleukin-6 signaling: opposing associations with susceptibility to COVID-19 and pneumonia
}

Susanna C. Larsson, $\mathrm{PhD}^{1,2}$, Stephen Burgess, $\mathrm{PhD},{ }^{3,4}$ Dipender Gill, BMBCh, $\mathrm{PhD}^{5-8}$

${ }^{1}$ Unit of Cardiovascular and Nutritional Epidemiology, Institute of Environmental Medicine, Karolinska Institutet, Stockholm, Sweden

${ }^{2}$ Department of Surgical Sciences, Uppsala University, Uppsala, Sweden

${ }^{3}$ Department of Public Health and Primary Care, University of Cambridge, Cambridge, United Kingdom

${ }^{4}$ MRC Biostatistics Unit, University of Cambridge, Cambridge, United Kingdom

${ }^{5}$ Department of Epidemiology and Biostatistics, School of Public Health, St Mary's Hospital, Imperial College London, London, United Kingdom

${ }^{6}$ Clinical Pharmacology and Therapeutics Section, Institute of Medical and Biomedical Education and Institute for Infection and Immunity, St George's, University of London, London, United Kingdom

${ }^{7}$ Clinical Pharmacology Group, Pharmacy and Medicines Directorate, St George's University Hospitals NHS Foundation Trust, London, United Kingdom.

${ }^{8}$ Novo Nordisk Research Centre Oxford, Old Road Campus, Oxford, United Kingdom

\section{Corresponding author:}

Susanna C. Larsson, $\mathrm{PhD}$

Unit of Cardiovascular and Nutritional Epidemiology

Institute of Environmental Medicine

Karolinska Institutet, 17177 Stockholm, Sweden

Tel: +46-8-52486059; Email: susanna.larsson@ki.se

Keywords: COVID-19; cytokines; interleukin-6; Mendelian randomization; pneumonia 


\begin{abstract}
The inflammatory cytokine interleukin-6 (IL-6) is pivotal for orchestrating the immune response. Inhibitors of IL-6 signaling are being investigated as treatments for severe coronavirus disease 2019 (COVID-19). We conducted a Mendelian randomization study investigating the effect of IL-6 signaling on susceptibility to COVID-19 and pneumonia. Our results showed that genetically proxied inhibition of IL-6 signaling was associated with reduced risk of COVID-19, but also with increased risk of pneumonia. Respiratory disease is a main feature of severe COVID-19, and the potential of IL-6 signaling inhibitors to increase risk of pneumonia warrants vigilance and caution in their application to treat COVID-19.
\end{abstract}


The inflammatory cytokine interleukin-6 (IL-6) is central to orchestrating the immune system. The pathophysiological process underlying severe coronavirus disease 2019 (COVID-19), caused by the severe acute respiratory syndrome coronavirus 2 , consists of an exaggerated host immune response and elevated circulating levels of inflammatory cytokines, including IL-6. ${ }^{1}$ As such, immunomodulatory agents are being investigated for the treatment of COVID-19. Glucocorticoids may limit inflammation-mediated lung injury in patients with severe COVID-19, and consequently reduce progression to respiratory failure and death. The RECOVERY trial found that administration of dexamethasone resulted in lower 28-day mortality among hospitalized COVID-19 patients who were receiving either invasive mechanical ventilation or oxygen alone at randomization, but not among those who were not receiving any respiratory support. ${ }^{2}$ Inhibition of IL-6 signaling may represent another potential immunomodulatory strategy for treating COVID- $19,{ }^{3}$ and a recent meta-analysis of mean IL-6 concentrations demonstrated 2.9-fold higher levels in patients with complicated COVID-19 compared with patients with non-complicated disease. ${ }^{4}$

Genetic variants that proxy inhibition of IL-6 signaling may be used as instrumental variables in the Mendelian randomization paradigm to investigate corresponding drug effects. Here, we conducted a Mendelian randomization investigation to assess the potential effect of pharmacological inhibition of IL-6 signaling on susceptibility to COVID-19 and pneumonia.

Inhibition of IL-6 signaling was proxied using seven single-nucleotide polymorphisms within or adjacent to the IL6R gene region that were associated with C-reactive protein (CRP; downstream molecule of IL-6 signaling) levels at the genome-wide significance threshold in 204402 individuals of European ancestry. ${ }^{5}$ These genetic variants also had associations with fibrinogen, IL-6 and soluble IL-6 receptor in a pattern consistent with their effect on reducing IL-6 signaling. ${ }^{5}$ 
Summary-level genetic data for COVID-19 were acquired from: 1) The COVID-19 Host Genetics Initiative genome-wide association meta-analysis (round 3), ${ }^{6}$ which included 6696 COVID-19 cases vs. 1073072 population controls, 3199 hospitalized COVID-19 cases vs. 897488 population controls, and 928 hospitalized COVID-19 cases vs. 2028 nonhospitalized COVID-19 controls; and 2) a genome-wide association study involving 1610 hospitalized patients with severe COVID-19, defined as having respiratory failure and requiring some degree of respiratory support, and 2205 control participants (healthy volunteers, blood donors and outpatients of gastroenterology departments) from seven hospitals in Italy and Spain. ${ }^{7}$ Corresponding data for pneumonia were obtained from: 1) the FinnGen consortium, including 15778 cases of all pneumoniae (International Statistical Classification of Diseases and Related Health Problems - 10th Revision codes: J12-J16, J18), and 119867 control participants; ${ }^{8}$ and 2) the UK Biobank cohort (through the MRC-IEU consortium via the MR-Base platform ${ }^{9}$ ), which included 6572 self-reported cases of pneumonia (id:UKB-b:4533) and 456361 control participants. The genetic association estimates in all studies were adjusted for sex and ancestry. Only summary-level data were analyzed in this study, for which appropriate ethical approval and participant consent had previously been obtained.

We performed summary data Mendelian randomization analysis using the inversevariance weighted method with multiplicative random-effects and accounting for correlations between genetic variants. Our results showed that genetically proxied inhibition of IL-6 signaling, scaled per 0.1 standard deviation lower CRP level, was associated with a reduced risk of COVID-19, but also with an increased risk of pneumonia (Figure 1).

Our findings provide evidence supporting that inhibition of IL-6 signaling reduces susceptibility to COVID-19. Importantly, they go further to provide genetic evidence that inhibition of IL-6 signaling may also increase susceptibility to pneumonia. While we 
considered a broad definition of pneumonia from any cause, our results may be of relevance to secondary lung infections that can complicate COVID-19. An adverse effect of IL-6 inhibition on risk of pneumonia risk is biologically plausible, and respiratory tract infections, including pneumonia, are a well-known complication of IL-6 signaling inhibition. ${ }^{10}$ Respiratory disease is a main feature of severe COVID-19, and the potential of IL-6 signaling inhibitors to increase risk of pneumonia warrants vigilance and caution in their application to treat COVID-19.

\section{Acknowledgments}

The authors thank the investigators of the COVID-19 genome-wide association study, the COVID-19 Host Genetics Initiative, and FinnGen consortium for sharing summary-level data.

\section{Contributors}

SCL, SB and DG contributed to the study design. SCL conducted statistical analyses. SCL and DG wrote the initial draft of the manuscript. All authors participated in the data interpretation and contributed to the final draft of the manuscript with intellectual importance.

\section{Funding}

SCL acknowledges research support from the Swedish Heart-Lung Foundation (HjärtLungfonden, 20190247), the Swedish Research Council (Vetenskapsrådet, 2019-00977), and the Swedish Research Council for Health, Working Life and Welfare (Forte, 2018-00123). SB is supported by a Sir Henry Dale Fellowship jointly funded by the Wellcome Trust and the Royal Society (204623/Z/16/Z). DG is supported by the British Heart Foundation Research Centre of Excellence (RE/18/4/34215) at Imperial College London. This work was supported by funding from the National Institute for Health Research (Cambridge Biomedical Research 
Centre at the Cambridge University Hospitals National Health Service Foundation Trust) [*].

*The views expressed are those of the authors and not necessarily those of the National

Health Service, the National Institute for Health Research or the Department of Health and Social Care.

\section{Competing interests}

DG is employed part-time by Novo Nordisk. The remaining authors have no conflicts of interest to disclose.

\section{REFERENCES}

1. McElvaney OJ, McEvoy N, McElvaney OF, Carroll TP, Murphy MP, Dunlea DM, Ni Choileain O, Clarke J, O'Connor E, Hogan G, Ryan D, Sulaiman I, Gunaratnam C, Branagan P, O'Brien ME, Morgan RK, Costello RW, Hurley K, Walsh S, de Barra E, McNally C, McConkey S, Boland F, Galvin S, Kiernan F, O'Rourke J, Dwyer R, Power M, Geoghegan P, Larkin C, O'Leary RA, Freeman J, Gaffney A, Marsh B, Curley GF and McElvaney NG. Characterization of the inflammatory response to severe COVID-19 illness. Am J Respir Crit Care Med. 2020.

2. Group RC, Horby P, Lim WS, Emberson JR, Mafham M, Bell JL, Linsell L, Staplin N, Brightling C, Ustianowski A, Elmahi E, Prudon B, Green C, Felton T, Chadwick D, Rege K, Fegan C, Chappell LC, Faust SN, Jaki T, Jeffery K, Montgomery A, Rowan K, Juszczak E, Baillie JK, Haynes R and Landray MJ. Dexamethasone in hospitalized patients with Covid-19 - Preliminary report. N Engl J Med. 2020.

3. Lan SH, Lai CC, Huang HT, Chang SP, Lu LC and Hsueh PR. Tocilizumab for severe COVID-19: a systematic review and meta-analysis. Int $J$ Antimicrob Agents. 2020:106103.

4. Coomes EA and Haghbayan H. Interleukin-6 in Covid-19: A systematic review and meta-analysis. Rev Med Virol. 2020:e2141.

5. Georgakis MK, Malik R, Gill D, Franceschini N, Sudlow CLM, Dichgans M and Invent Consortium CIWG. Interleukin-6 Signaling Effects on Ischemic Stroke and Other Cardiovascular Outcomes: A Mendelian Randomization Study. Circ Genom Precis Med. 2020;13:e002872.

6. Covid-19 Host Genetics Initiative. The COVID-19 Host Genetics Initiative, a global initiative to elucidate the role of host genetic factors in susceptibility and severity of the SARS-CoV-2 virus pandemic. Eur J Hum Genet. 2020;28:715-718.

7. Ellinghaus D, Degenhardt F, Bujanda L, Buti M, Albillos A, Invernizzi P, Fernandez J, Prati D, Baselli G, Asselta R, Grimsrud MM, Milani C, Aziz F, Kassens J, May S, Wendorff M, Wienbrandt L, Uellendahl-Werth F, Zheng T, Yi X, de Pablo R, Chercoles AG, Palom A, Garcia-Fernandez AE, Rodriguez-Frias F, Zanella A, Bandera A, Protti A, Aghemo A, Lleo A, Biondi A, Caballero-Garralda A, Gori A, Tanck A, Carreras Nolla A, Latiano A, Fracanzani AL, Peschuck A, Julia A, Pesenti A, Voza A, Jimenez D, 
Mateos B, Nafria Jimenez B, Quereda C, Paccapelo C, Gassner C, Angelini C, Cea C, Solier A, Pestana D, Muniz-Diaz E, Sandoval E, Paraboschi EM, Navas E, Garcia Sanchez F, Ceriotti F, Martinelli-Boneschi F, Peyvandi F, Blasi F, Tellez L, Blanco-Grau A, Hemmrich-Stanisak G, Grasselli G, Costantino G, Cardamone G, Foti G, Aneli S, Kurihara H, ElAbd H, My I, Galvan-Femenia I, Martin J, Erdmann J, Ferrusquia-Acosta J, Garcia-Etxebarria K, Izquierdo-Sanchez L, Bettini LR, Sumoy L, Terranova L, Moreira L, Santoro L, Scudeller L, Mesonero F, Roade L, Ruhlemann MC, Schaefer M, Carrabba M, Riveiro-Barciela M, Figuera Basso ME, Valsecchi MG, Hernandez-Tejero M, Acosta-Herrera M, D'Angio M, Baldini M, Cazzaniga M, Schulzky M, Cecconi M, Wittig M, Ciccarelli M, Rodriguez-Gandia M, Bocciolone M, Miozzo M, Montano N, Braun N, Sacchi N, Martinez N, Ozer O, Palmieri O, Faverio P, Preatoni P, Bonfanti P, Omodei P, Tentorio P, Castro P, Rodrigues PM, Blandino Ortiz A, de Cid R, Ferrer R, Gualtierotti R, Nieto R, Goerg S, Badalamenti S, Marsal S, Matullo G, Pelusi S, Juzenas S, Aliberti S, Monzani V, Moreno V, Wesse T, Lenz TL, Pumarola T, Rimoldi V, Bosari S, Albrecht W, Peter W, Romero-Gomez M, D'Amato M, Duga S, Banales JM, Hov JR, Folseraas T, Valenti L, Franke A, Karlsen TH and Severe Covid GG. Genomewide Association Study of Severe Covid-19 with Respiratory Failure. N Engl J Med. 2020.

8. FinnGen consortium. FinnGen Documentation of R3 release, 2020. Web: https://finngen.gitbook.io/documentation/ [accessed July 31, 2020].

9. Hemani G, Zheng J, Elsworth B, Wade KH, Haberland V, Baird D, Laurin C, Burgess S, Bowden J, Langdon R, Tan VY, Yarmolinsky J, Shihab HA, Timpson NJ, Evans DM, Relton C, Martin RM, Davey Smith G, Gaunt TR and Haycock PC. The MR-Base platform supports systematic causal inference across the human phenome. Elife. 2018;7: pii: e34408.

10. Smolen JS, Schoels MM, Nishimoto N, Breedveld FC, Burmester GR, Dougados M, Emery P, Ferraccioli G, Gabay C, Gibofsky A, Gomez-Reino JJ, Jones G, Kvien TK, Murakami M, Betteridge N, Bingham CO, 3rd, Bykerk V, Choy EH, Combe B, Cutolo M, Graninger W, Lanas A, Martin-Mola E, Montecucco C, Ostergaard M, Pavelka K, Rubbert-Roth A, Sattar N, Scholte-Voshaar M, Tanaka Y, Trauner M, Valentini G, Winthrop KL, de Wit M and van der Heijde D. Consensus statement on blocking the effects of interleukin- 6 and in particular by interleukin-6 receptor inhibition in rheumatoid arthritis and other inflammatory conditions. Ann Rheum Dis. 2013;72:48292. 
medRxiv preprint doi: https://doi.org/10.1101/2020.09.15.20165886; this version posted September 18, 2020. The copyright holder for this preprint (which was not certified by peer review) is the author/funder, who has granted medRxiv a license to display the preprint in perpetuity.

It is made available under a CC-BY 4.0 International license .

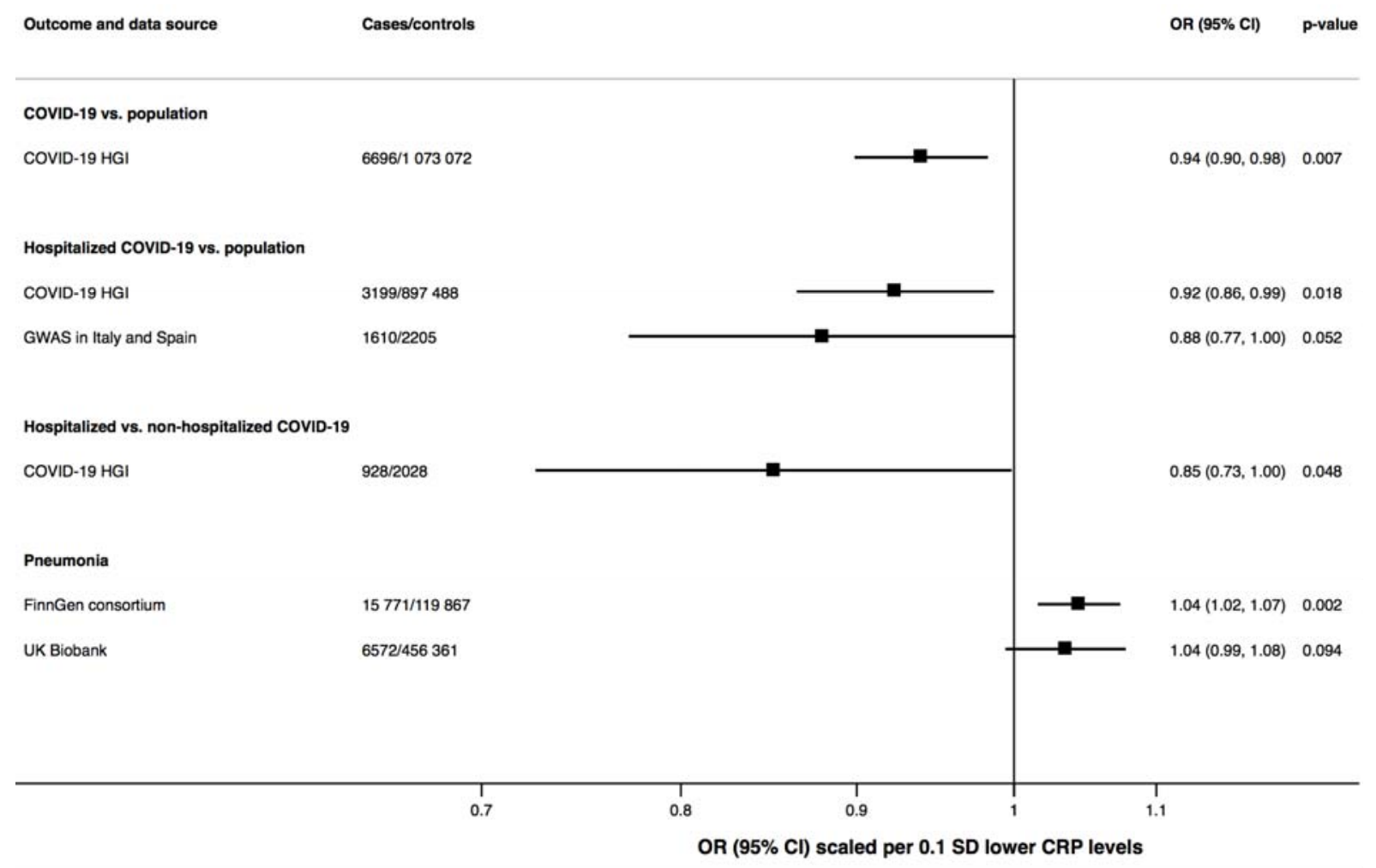

Figure 1. Associations of genetically proxied inhibition of IL-6 signaling with susceptibility to COVID-19 and pneumonia. Estimates were derived using the multiplicative random-effects inverse variance weighted method and accounting for the correlations between the seven genetic variants in or near the IL6 gene region. CI, confidence interval; CRP, C-reactive protein; GWAS, genomewide association study; HGI, Host Genetics Initiative; OR, odds ratio; SD, standard deviation. 